\title{
RESUMO
}

\section{LEITURAS SOBRE A REPRODUÇ̃̃O DE ESTEREÓTIPOS DE GÊNERO NA ATUAÇÃO JUDICIAL}

\section{READINGS ON THE REPRODUCTION OF GENDER STEREOTYPES IN JUDICIAL ACTIONS}

\section{LECTURAS SOBRE LA REPRODUCCIÓN DE ESTEREOTIPOS} DE GÉNERO EN LA ACTUACIÓN JUDICIAL
Com este artigo, busco fazer uma revisão bibliográfica sobre a reprodução de estereótipos de gênero por parte dos atores do sistema de justiça, a fim de refletir sobre como o direito lida com a questão de gênero, de um modo geral, mas também diante da prática criminosa e da subversão dos papéis de gênero por parte das mulheres. Com base na revisão de literatura, apresento uma reflexão sobre a atuação de atores do sistema de justiça, tais como promotores/as, juízes/as e defensores/as públicos/ as em casos que envolvem o encarceramento de mulheres grávidas e mães.

\section{PALAVRAS-CHAVE}

Estereótipos de Gênero. Sistema de Justiça. Mulheres Grávidas. Prisão Domiciliar. 


\section{ABSTRACT}

With this article, I seek to make a bibliographical review on the reproduction of gender stereotypes by the actors of the justice system, in order to reflect on how the law deals with the gender issue in general, but also with criminal practice and subversion of gender roles by women. With the present article I intend to carry out a bibliographical review in order to base the reflection on the performance of the justice system, such as prosecutors, judges and public defenders in cases involving the incarceration of pregnant women and mothers.

\section{KEYWORDS}

Gender Stereotypes. System of Justice. Pregnant Women. Home Prison.

\section{RESUMEN}

Con este artículo, busco hacer una revisión bibliográfica sobre la reproducción de estereotipos de género por parte de los actores del sistema de justicia, a fin de reflexionar sobre cómo el derecho trata con la cuestión de género, de un modo general, pero también ante la práctica criminal y de la subversión de los roles de género por parte de las mujeres. Con base en la revisión de la literatura presento una reflexión sobre la actuación de actores del sistema de justicia, tales como promotores/ as, jueces/juezas y defensores/as públicos/as en casos que involucran el encarcelamiento de mujeres embarazadas y madres.

\section{PALABRAS CLAVE}

estereotipos de género; sistema de justicia; mujeres embarazadas; arresto domiciliario. 


\section{INTRODUÇ̧̃̃o}

Este trabalho foi escrito a partir de debates promovidos em sala de aula na disciplina Gênero e Direito, oferecida pela professora Salete Maria da Silva no PPGNEIM/UFBA, no semestre letivo 2018.2, bem como a partir de estudos realizados no bojo de pesquisa acadêmica por meio da qual proponho pensar sobre a maternidade negra, tendo em vistas o numeroso encarceramento de mulheres mães e grávidas, apesar da previsão legal de medida cautelar de prisão domiciliar nesses casos. Com o presente artigo, pretendo realizar uma revisão bibliográfica a fim de embasar a reflexão sobre a atuação de atores do sistema de justiça, como promotores/as, juízes/as e defensores/as públicos/as em casos que envolvem o encarceramento de mulheres grávidas e mães.

É fundamental, considerando o significativo aumento do encarceramento de mulheres no Brasil, voltar o olhar para o impacto da atuação do sistema de justiça na construção dessa realidade. A incidência das instância policial sobre as vidas de mulheres negras e pobres é maior, contudo, há que se pensar sobre a chancela dada pelo sistema de justiça por meio da instituição da prisão e do manejo de instrumentos legais que possibilitariam medidas menos gravosas, mas que nem sempre são observados.

\section{CONTEXTO DE MORTE, ENCARCERAMENTOE NEGATIVA DE DIREITOS}

Assim como as mortes sistemáticas e o encarceramento massivo de jovens homens negros, é crescente no país o encarceramento de jovens mulheres negras. Pesquisas indicam que enquanto jovens homens negros têm sido alvos preferenciais nas ações policiais que os aprisionam e matam, as cifras que representam o encarceramento de mulheres crescem a cada $a n 0^{2}$. É possível dimensionar o crescimento da população carcerária feminina ante os dados apresentados pelo Levantamento Nacional de Informações Penitenciárias (SANTOS; VITTO, 2014), do Ministério da Justiça, sobre a variação no número de mulheres presas entre os anos de 2007 e 2014, os quais indicam um aumento de $96 \%$ do número de mulheres presas, em todo o país.

$\mathrm{Na}$ Bahia, onde o quadro não é tão diferente do nacional, mortes e encarceramentos crescentes anualmente são uma realidade para homens e mulheres negros e negras, contabilizando-se um aumento de $94 \%$ no número de mulheres presas nesse período.

Entre os anos de 2000 e 2014, o crescimento no número de mulheres encarceradas foi contabilizado em 564,4\%, em todo o Brasil - número superior à média nacional de $220,20 \%$ no crescimento da

\footnotetext{
20 Instituto de Pesquisa Econômica Aplicada (IPEA) aponta para alta taxa de mortalidade de jovens negro resultado do alto grau de letalidade das polícias brasileiras, conforme dados do Ministério do Planejamento, Desenvolvimento e Gestão. (CERQUEIRA et al., 2018). Ao mesmo tempo, dados referentes ao encarceramento nos últimos anos dão conta que o perfil do encarcerado é de jovens homens negros, faixa etária entre 20 e 29 anos de idade.
} 
população carcerária masculina (SANTOS; VITTO, 2014). O INFOPEN ${ }^{3}$ aponta que, em todo o Brasil, a população de mulheres negras presas corresponde a $64 \%$ do total de encarceradas (SANTOS; VITTO, 2014). Na Bahia, a imensa maioria das mulheres presas é negra, correspondendo a $94 \%$ delas. Segundo o estudo, as mulheres presas brasileiras são, em sua grande maioria, mulheres negras, jovens, com filhos e responsáveis pelo sustento dos seus lares antes da prisão.

Apresentada como motor para a redução de tais números e possível solução para o problema do hiperencarceramento de mulheres, a prisão domiciliar é uma medida cautelar com previsão legal especificamente direcionada às mulheres presas grávidas ou mães de crianças menores de 12 anos de idade, tendo por objetivo assegurar que as mães tenham acesso a cuidados à saúde no período da gestação e que crianças não nasçam e cresçam no ambiente prisional, ou sem os cuidados da mãe. No entanto, há dados a apontar um número considerável de mulheres presidiárias que foram presas grávidas e que tiveram seus filhos na prisão.

Tratam-se, sabidamente, de mulheres negras encarceradas sem acesso à prisão domiciliar. Segundo o Conselho Nacional de Justiça, o Cadastro Nacional de Presas Grávidas e Lactantes (BANDEIRA; ANDRADE, 2018) levantou a presença de 622 mulheres nestas situações em todo o Brasil. Segundo a mencionada instituição, o censo carcerário de 2017 teria revelado que o perfil das mulheres que tiveram filho na prisão é de mulheres jovens, $70 \%$ entre 20 e 29 anos, solteiras, 56\%, e em sua maioria negra, $70 \%$ delas são pretas ou pardas.

Apesar de trazer dados importantes sobre a presença de mulheres negras grávidas e em fase de aleitamento no cárcere, o levantamento não registra o número de mulheres com filhos recém nascidos sob os cuidados de familiares, nem o número de mulheres que podem estar no início de uma gravidez, mas que não o sabem por não ter acesso a serviços médicos dentro dos presídios. Da mesma forma, ao centrar na gravidez e lactância, o levantamento não dá conta de registrar o número de mulheres mães de filhos menores de 12 anos, presumidamente dependentes da presença materna.

No entanto, ainda que não seja possível dimensionar a quantidade com exatidão e que existam outros critérios a serem considerados para a determinação ou não da medida cautelar de prisão domiciliar, chama atenção o número tão destacados de mulheres negras dando à luz nas prisões, deixando de ter acesso a uma medida cautelar, apesar de atender aos critérios legais objetivos relativos à maternidade.

\section{RELAÇÃO DIREITO E GÊNERO: A PRISÃO DOMICILIAR EM PERSPECTIVA}

Ao tempo em que são construídos estereótipos associados ao comportamento feminino, os quais qualificam mulheres como passivas, seguidoras e emocionais, qualidades transformadas em símbolos universais de feminilidade, a maternidade é socialmente tratada como ápice da existência das mulheres. Assim, a sociedade costuma santificar a maternidade, buscando protegê-la de diversas formas, sendo o Direito uma das ferramentas dessa proteção e um instrumento pensado e construído a

3 Sistema de informações estatísticas do sistema penitenciário brasileiro. 
partir de perspectiva androcêntrica (CAMPOS, 2017; SILVA, 2018), cabe pensar sobre a relação entre direito e feminismo, considerando as contribuições do feminismo para o Direito.

Ao tratar da incorporação da noção de gênero no direito, Carmen Hein Campos, identifica as ondas feministas no direito, afirmando que as diferentes abordagens do feminismo estiveram calcadas em debates sobre "o sistema sexo/gênero, a igualdade/diferença e o público/privado" (CAMPOS, 2017, p. 159). A primeira onda, com marco nos anos 1960, seria caracterizada pela crença na igualdade formal, defesa da cidadania igualitária, na qual os direitos seriam acessados da mesma forma por todas as pessoas, o que sustentaria a ideia de que homens e mulheres deveriam ter tratamentos iguais. Nos anos 1980, a segunda onda foi marcada pela crítica ao tratamento igualitário formal, por ter como referência a vida dos homens e não dar respostas as diferenças existentes entre homens e mulheres (CAMPOS, 2017, p. 159).

Segundo Campos, nos anos 1980 o debate sobre igualdade e diferença foi intenso entre as feministas do direito, sendo que "a questão fundamental era se as mulheres eram iguais ou diferentes dos homens, isto é, se as mulheres deveriam receber tratamento legal igualitário (sendo iguais aos homens) ou proteção especial (sendo diferente dos homens)" (CAMPOS, 2017, p. 160). Segundo a autora, o contexto de luta contra a ditadura militar no país e o processo de redemocratização são fundamentais para a consolidação e desenvolvimento dos debates feministas no direito, ganhando destaque as discussões sobre o tratamento dado pelo sistema de justiça aos casos de violência doméstica (CAMPOS, 2017).

A relação entre direito e feminismo também é trabalhada por Salete Maria da Silva (2018), que faz uma introdução ao conceito de feminismo jurídico, reivindicando o uso do termo para indicar a atuação voltada para a superação da lógica androcêntrica do Direito e com vistas a instaurar uma nova perspectiva que promova a igualdade entre os gêneros por meio da seara jurídica. A autora aponta que o termo é pouco utilizado no contexto da América Latina e critica o uso de expressões como teoria feminista do direito ou pensamento jurídico feminista que, segundo a autora, ao buscar expressar a relação entre gênero e direito, tendem a enfatizar excessivamente a abordagem acadêmica, deixando de referenciar outras formas de atuação como a ação política em movimentos sociais (SILVA, 2018, p. 89).

Segundo Silva (2018) o feminismo jurídico se expressa de forma múltipla na ação e reflexão feministas, sendo conceituado pela autora como "um conjunto de críticas, teorizações, proposições metodológicas e atividades práticas desenvolvidas por juristas feministas em face do fenômeno jurídico, dentro e fora do sistema de justiça” (SILVA, 2018, p. 90). Surgido nos EUA na década de 1970 e na América Latina na década de 1990, aqui ganhando força no contexto de redemocratização dos países da região, hoje o foco do feminismo jurídico tem sido o uso estratégico de leis, somando-se à denúncia do sistema de justiça e à ação no seu âmbito, como as principais formas de atuação no feminismo jurídico (SILVA, 2018, p. 90).

Cabe considerar que, trazendo essa discussão para a reflexão sobre a previsão de adoção de medida cautelar em casos de prisão de mulheres mães grávidas, a prisão domiciliar, em caso de gravidez, garante tratamento diferenciado às mulheres mães, contudo, pode servir para reforçar o papel de 
gênero associado à maternidade. A lei de medidas cautelares e a previsão de prisão domiciliar trazem a possibilidade de atuação estratégica, tendo em vistas garantir melhores condições de exercício da gravidez para as mulheres presas mães, contudo cabe pensar sobre os limites desta previsão legal no que diz respeito às discussões sobre gênero e direito.

A prisão domiciliar está longe de ser tida como solução ideal, já que a mesma compõe a dinâmica do encarceramento, no entanto, pragmaticamente, pode representar uma possibilidade de acesso a condições dignas de exercício da gravidez diante das condições degradantes às quais mulheres e crianças negras são submetidas nas prisões brasileiras. Cabe, em acordo com a perspectiva de Angela Davis (2018), perceber o desafio de lutar por ambientes mais humanos e menos degradantes no contexto das prisões, sem endossar, contudo, a permanência e a necessidade do sistema prisional.

\section{ESTEREÓTIPOS SE FAZEM PRESENTES SEJA A MULHER VÍTIMA OU AUTORA}

Acerca da atuação judicial e a reprodução de estereótipos de gênero, a pesquisa de Livya Ramos de Barros (2014) investiga critérios adotados por magistrados em suas decisões, relacionados ao comportamento de mulheres vítimas de estupro e dos homens acusados desses crimes contra elas. A autora questiona quais relações sociais produzem a convenção jurídica de análise do comportamento da vítima de crime de estupro como um do aspectos determinantes para a aplicação da pena. Por meio da análise de discurso presentes em decisões judiciais, a pesquisadora trabalha com a hipótese de classificação das vítimas pelos juízes durante o processo decisório, sendo algumas delas identificadas como merecedoras de respeito enquanto outras não são.

A autora identificou que na fundamentação das sentenças judiciais por ela investigadas, as características pessoais dos envolvidos no crime, tanto vítima, quanto acusado, podem ser usadas como motivadoras do ato violento (BARROS, 2014), pois os dados evidenciaram que as autoridades consideraram os "antecedentes criminais, depoimento da vítima, virgindade, gravidez, ocupação/profissão, prostituição, vida pregressa, comportamento liberal, roupas inadequadas, comportamento provocante, além de outros aspectos” (BARROS, 2014, p. 1185). Assim, tanto vítimas quanto acusados são analisados quanto a seu comportamento, personalidade, vida sexual e condição financeira.

Segundo a mencionada autora, é evidente o processo de revitimização que envolve atuação dos atores do sistema de justiça, o qual se faz presente no trato destinado à vítima, principalmente nos questionamentos feitos por delegados, promotores, médicos e juízes, os quais, em geral, buscam sondar sobre o comportamento pessoal e trajetória familiar da vítima mulher. Nos crimes de estupro, em função da dificuldade de comprovação, valoriza-se a palavra da vítima, contudo, ao analisar as decisões judiciais, a autora pontua ter percebido a relativização da relevância da palavra das mulheres, de maneira que a confiabilidade do que é dito por ela depende bastante do contexto em que se encontra (BARROS, 2014).

No que diz respeito ao autor do delito, segundo a pesquisa mencionada, há uma tendência na atuação judicial a relacionar a conduta do acusado com a presença de distúrbio mental, depravação, ou 
experiência contumaz no mundo do crime. Quando tais características não podem ser percebidas na conduta do acusado, busca-se no comportamento da vítima a justificativa para o acontecido (BARROS, 2014). A autora observa que, de modo geral, os juízes analisam comportamentos dos envolvidos no crime, vítima e acusado, em busca de padrões de comportamento que auxiliem na tomada de sua decisão.

O trabalho de Ana Paula Sciammarella (2017) reflete sobre o manejo da categoria "violência de gênero", presente no texto da Lei Maria da Penha (Lei 11.340/06), por operadores do sistema de justiça. A autora faz uma análise a partir de decisões jurisprudenciais sobre o tema, à luz da teoria sistêmica de Luhmman.

Sciammarella ao utilizar a teoria dos sistemas de Luhmann para falar do caráter auto regulador do sistema de justiça, destaca a importância de se pensar o funcionamento do referido sistema e, a partir disto, calcular a possibilidade de interferência nessa esfera. Isso porque, segundo a autora, o conceito de violência de gênero inserido na Lei Maria da Penha esbarraria nos limites de aplicação da lei impostos pela própria dinâmica do sistema jurídico, o qual tende a interpretar conceitos, tomando o próprio direito como referência (SCIAMMARELLA, 2017).

Ao realizar uma análise de decisões judiciais em casos de violência doméstica e do uso da Lei Maria da Penha por juízes, a autora analisa como o conceito de violência de gênero é manejado pelos juízes, por vezes desconsiderando as ponderações feitas pela equipe multidisciplinar, criando uma linha própria de tradução do conceito, por meio da aproximação de conceitos com os quais se está mais habituado, assim,

[...] se a LMP propõe as relações íntimas entre homens e mulheres como de poder, e a violência contra a mulher como resultante da forma historicamente desigual, em suas decisões os atores do sistema de justiça buscam relacionar o conceito de gênero com categorias já conhecidas pelo universo jurídico como a ideia de hipossuficiência. (SCIAMMARELLA, 2017, p. 56).

Sobre o exercício da maternidade no cárcere e a atuação judicial ante a prisão de mulheres mães, o trabalho de Raíssa Silvério (2017) busca analisar as representações sociais que marcam essas mulheres, a partir da condição de mãe e de encarcerada. A pesquisadora faz uma análise teórica acerca do exercício da maternidade nas prisões brasileiras, partindo de uma análise sobre a construção social da maternidade e quais as repercussões da leitura social do papel materno na realidade de mulheres presas. A autora aponta que a criminalidade feminina representa o rompimento de padrões de gênero e, tende a ser lido socialmente como uma conduta patologizada e passível de tratamento (SILVÉRIO, 2017, p. 62), sendo as representações sociais de mãe e criminosa inconciliáveis.

Em sentido semelhante, Naila Ingrid Chaves, produziu um estudo sobre a aplicação da cautelar de prisão domiciliar pelo TJSP em casos de mulheres mães presas. A autora afirma que as figuras de mãe e criminosa são irreconciliáveis e que

identificou em sua pesquisa duas tendências de julgamento, uma que toma a maternidade como possibilidade de salvação moral da mulher criminosa, oportunidade para reaver sua condição feminina; outra que considera a prática criminosa incompatível com o exercício da maternidade, o que faria 
com que a mulher criminosa não fosse imprescindível aos cuidados de uma criança (CHAVES, 2016).

Apesar da impossibilidade de conciliação entre essas duas imagens da mulher, Naila Ingrid Chaves (2016, p. 351)aponta para existência de um dualismo que cerca a mulher que é mãe e que praticou um delito, posto que esta ao cometer um crime rompe com as expectativas de gênero, mas tem a possibilidade de reconstruí-las por meio do exercício da maternidade. A autora pressupõe que as maternidades são valoradas socialmente de forma diferente, e parte do conceito de hierarquias reprodutivas para afirmar que a aceitação da maternidade depende de uma série de aspectos que marcam a vida da mulher como raça, classe, sexualidade, idade.

A pesquisadora indica que, de modo geral, há uma rigidez no trato legal por parte dos magistrados e uma valorização da pretensão punitiva por parte dos operadores do direito, o que prejudica o acesso das mulheres à prisão domiciliar. Por exemplo: há uma tendência nos julgamentos à concessão dessa medida cautelar apenas em casos extremos de risco à saúde das mulheres grávidas, devido às condições da prisão ou ao estado avançado da gravidez (CHAVES, 2016, p. 371); a autora, também, pontua que há um apego excessivo dos magistrados ao aspecto temporal que estabelece a concessão da prisão domiciliar a partir do $7^{\circ}$ mês de gravidez, o que também dificultaria o acesso das mulheres grávidas à cautelar em tempo hábil.

\section{CONCLUSÕES}

Diante de contexto de encarceramento crescente de mulheres, é fundamental pensar sobre a atuação do sistema de justiça e seu papel na conformação desse quadro. Os resultados e observações presentes em estudos sobre estereótipos de gênero e encarceramento de mulheres nos auxilia a pensar sobre como o sistema de justiça atua por meio da reprodução de estereótipos em casos que envolvem a presença de mulheres, seja na condição de vítima ou de autoras de delitos. Ao mesmo tempo, nos possibilita pensar sobre os limites do manejo de previsões legais que buscam garantir direitos às mulheres, o que pode servir de referência para se pensar a utilização da lei das cautelares no que diz respeito à prisão domiciliar de mulheres mães.

\section{REFERÊNCIAS}

\section{BANDEIRA, Regina; ANDRADE, Paula. Brasil tem 622 grávidas ou lactantes em presídios.} Conselho Nacional de Justiça, 25 jan. 2018. Disponível em: http://www.cnj.jus.br/noticias/ cnj/86062-brasil-tem-622-gravidas-ou-lactantes-em-presidios. Acesso em 15 set. 2018.

BARROS, Livya Ramos Sales Mendes de. Umas e outras: a presença de estereótipos de gênero no Sistema de Justiça Penal e a classificação das mulheres vítimas de crimes de estupro a partir da fala e do comportamento. Encontro da REDOR, 18, 2014. Anais [...], , Recife, 2014. p. 1183-1204. 
BRAGA, Ana Gabriela; FRANKLING, Naila Ingrid Chaves. Quando a casa é a prisão: uma análise de decisões de prisão domiciliar de grávidas e mães pós a lei 12.403/2011. Revista Quaestio Juris, Rio de Janeiro, v. 9, n. 1, p. 349-375, 2016.

CAMPOS, Carmen Hein. A teoria feminista do direito. Teoria feminista e crítica às criminologias. Rio de Janeiro: Lumen Juris, 2017. p. 159/216.

DAVIS, Angela. Estarão as prisões obsoletas? São Paulo: Difel, 2018.

CERQUEIRA, Daniel (coord.). et al. Atlas da Violência 2018. Fórum Brasileiro de Segurança Pública. Rio de Janeiro: IPEA; FBSP, junho de 2018. Disponível em: http://www.ipea.gov.br/portal/images/ stories/PDFs/relatorio_institucional/180604_atlas_da_violencia_2018.pdf. Acesso em: 15 set. 2018

SANTOS, Thandara; VITTO, Renato Campos Pinto de. Levantamento Nacional de informações penitenciárias: INFEP mulheres. Departamento Penitenciário Nacional - Ministério da Justiça, junho 2014. Disponível em: https://www.justica.gov.br/news/estudo-traca-perfil-da-populacaopenitenciaria-feminina-no-brasil/relatorio-infopen-mulheres.pdf. Acesso em: 27 out. 2017.

SCIAMMARELLA, Ana Paula. Mobilização feminista, violência de gênero e práticas judiciais no Brasil: reflexões à luz das teorias dos sistemas sociais. Revista Punto Género, n. 7, p. 46-68, maio 2017.

SILVA, Salete Maria; WRIGHT, Sonia Jay. Uma reflexão feminista sobre o conceito de justiça de gênero. Revista de Teorias da Justiça, da Decisão e da Argumentação Jurídica, Brasília, v. 2, n. 1 p. 1-27, jan./jun., 2016.

SILVA, Salete Maria. Feminismo jurídico: uma introdução. Cadernos de gênero e diversidade, Salvador, v. 4, n. 1, jan./mar. 2018

SILVÉRIO, Raíssa Lemos; SANTOS FILHO, José dos Reis. A presa e a mãe: representações sociais no universo prisional. Revista Sem Aspas, Araraquara, v. 6, n. 1, p. 56-73, jan./jun. 2017. 


\section{(2) (1) (-)}

Este artigo é licenciado na modalidade acesso abertosob a Atribuição-Compartilhalgual CC BY-SA 